INTERNATIONAL JOURNAL OF

MULTIDISCIPLINARY STUDIES IN ARCHITECTURE

AND CULTURAL HERITAGE

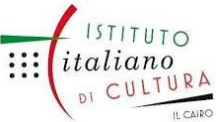

\title{
Managing Urban Districts Attached to Heritage Sites Case Study: The Pyramids Heritage District
}

Hossam Eldin Sabry M. Hegazi a, *

a Lecturer, The Architectural Department, Faculty of Fine Arts, Minya University

\begin{abstract}
Urban development is considered one of the most sustainable development pillars. It focuses on enhancing the quality of life for local communities. When new urban districts are attached to heritage districts, the communities of the new districts make greater impact on the heritage districts. This is where it gets complicated, since a strict balance is needed to apply urban development while conserving the heritage districts themselves. Many heritage sites have a great problem, which is urban interference with the heritage zones at site borders. This is what happened in The Pyramids heritage district, which was affected by The Pyramids Gardens neighborhood and Kafr El Gabal, Kafr Ghataty and Nazlet El Seman areas. This resulted into urban pressure on the infra-structure, causing negative impact on the heritage site. This is the main research problem, while the research objective is to make an assessment to manage urban districts, which are attached to heritage districts. The proposed management approach can balance between development and conservation, by following the approach of analytic study.

\begin{tabular}{ll}
\hline Keywords & \\
- & Urban Districts. \\
- & Attached Zones. \\
- & Heritage Districts. \\
$-\quad$ & Management. \\
\hline
\end{tabular}
\end{abstract}

\section{Introduction}

The Pyramids, a product of Egyptian creativity and designed as tombs, represented the engineering progress in Egyptian civilization; from aspects of buildingstructure, size, location, and orientation which is strongly related to the reflection of sun rays and its relevance to seasonal calculations such as the time of harvest. The secret composition of the pyramids raised a lot of inquires; in addition to the mystery of maneuvering for putting the huge stones on such great height, while other tombs reside inside caves located all over the district. All of this made The Pyramids district a witness on the beliefs of life and death, where the 
district has become an exceptionalrepresentation of the ancient Egyptian civilization. This district also witnessed many historic incidents added to the construction of the pyramids, such as the coronation of kings at Memphis. It is connected to the city of workers and represents the necropolis design concept of the pyramids as tombs ${ }^{1}$.

\subsection{Research Problem}

The urban districts attached to heritage districts can cause negative impact on thevaluable heritage area because of mismanagement of land use.

\subsection{Research Objective}

To make a work plan that can preserve the historic district from the new added urbanareas through a management approach.

\section{The Pyramids heritage district}

This district refers to the first civilization ever known on earth, where Memphis was the capital of Egypt during the time of The Old Kingdom, between 2700 and 2150

B.C. This district played a significant role in the history of architecture between the time of the Pharaohs up to the Greco-Romans, even 
Alexander The Great had receivedhis throne here at Memphis. The three pyramids (Khufu - Khafre - Menkaure) were constructed in 2500 B.C, added to The Sphinx, the city of workers and several necropolis stones; as well as other pyramids located between Giza and Dahshour. The most unique masterpiece of this site is Khufu Pyramid, which is known as The Great Pyramid of Giza and considered to be one of the seven wonders of the world. ${ }^{2}$ [ Figures 1,2]
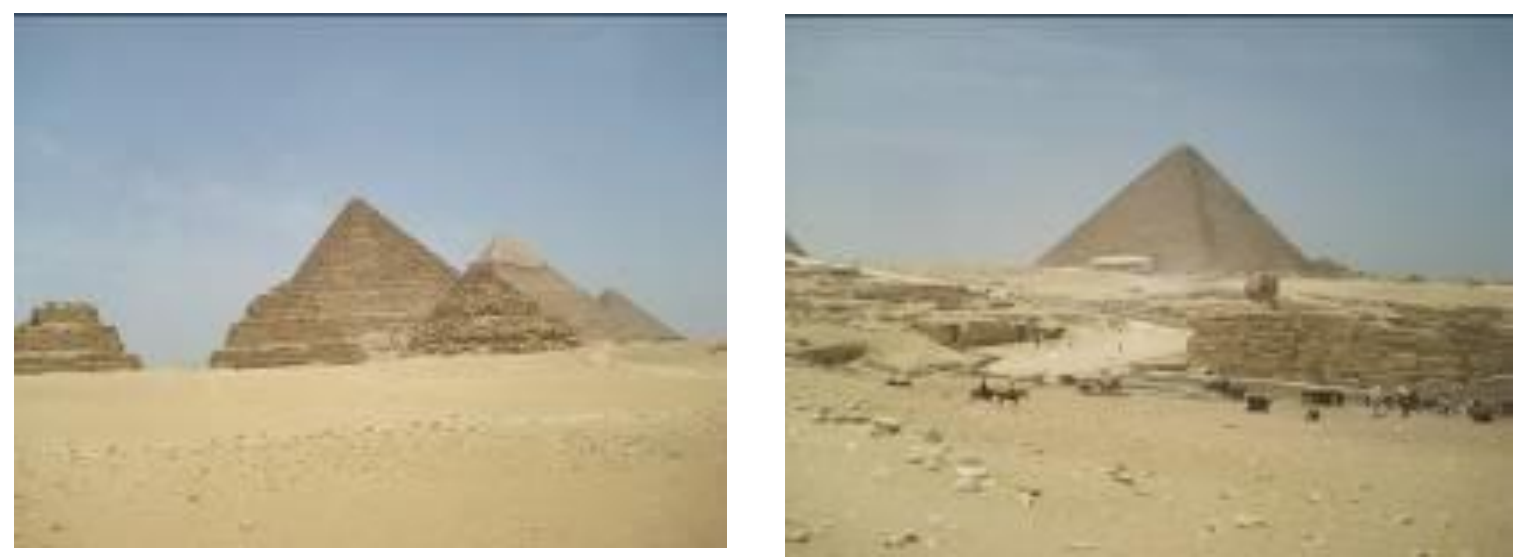

Figures 1, 2: The Sphinx and The Pyramids 


\section{Source: Researcher}

\section{State of conservation}

The district is considered in a good state of conservation, since a preventive conservation approach is usually implemented to the pyramids one by one. Also many conservation projects are being launched to sites like Saqqara and The Sphinx. It is obvious that the chosen district in the case study is a point of focus on the side of stakeholders and international entities, since it doesn't just represent a cultural value, but also an economic one due to its touristic value; making it a source of nationalincome. ${ }^{3}$ [ Figure 3]

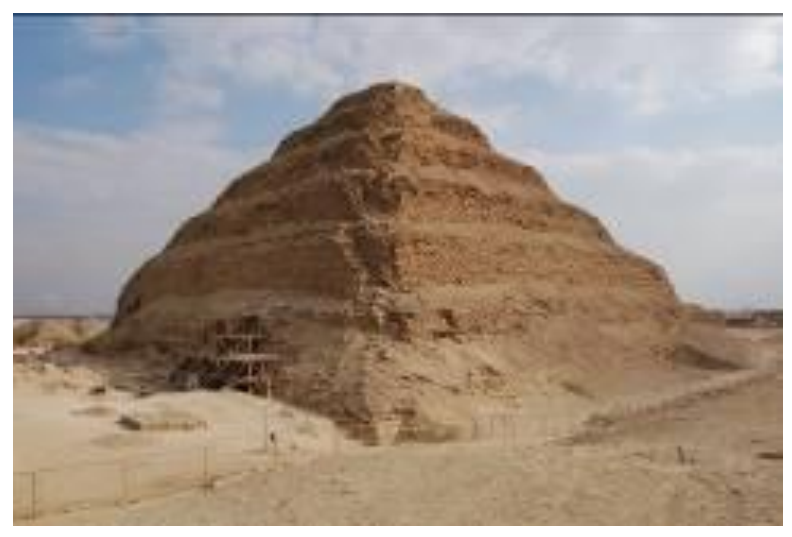

Figure 3: Saqqara Pyramid conservation projectSource: Researcher 


\section{Development pressure indicators on the district of study}

The district suffers from urban crawling on its borders which should be carefully monitored ${ }^{4}$. This is clear at the neighborhood expansions of Nazlet El Semanand Kafr El Gabal areas, where each area has expanded separately then all the new expansions got connected to each other, and to the eastern part at the Nobles tombs. The northern part of the heritage district also received urban pressure from the presence of the Mina House Oberoi hotel and two sports clubs. Even the touristic bazars in the area have contributed to this pressure which has generated from theurban crawling that in turn forced the stakeholders to make fences around the district.It is positive though that those fences contain cameras and gates to control entrances, in addition to spotting the new urban communities in trials of expansion. Other forms of pressure that appeared in the area were a result of human use, such as the construction of The Ring Road and the subway to serve the urban communities, wherethese projects were strictly opposed by UNESCO as a protection procedure of the district which is considered a world heritage site. ${ }^{5}$ [ Figure 4, 5, 6,7] 

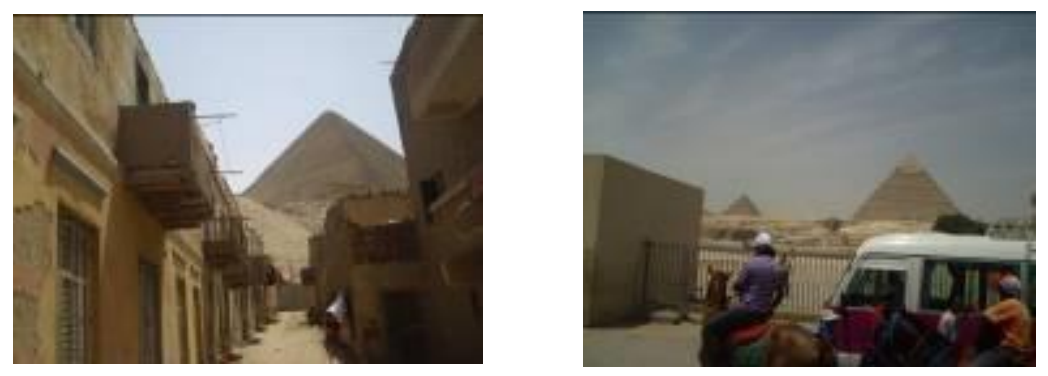

Figures 4, 5, 6, 7: Results ofneighborhoods pressure onthe district (unplanned animals move and urban crawl)
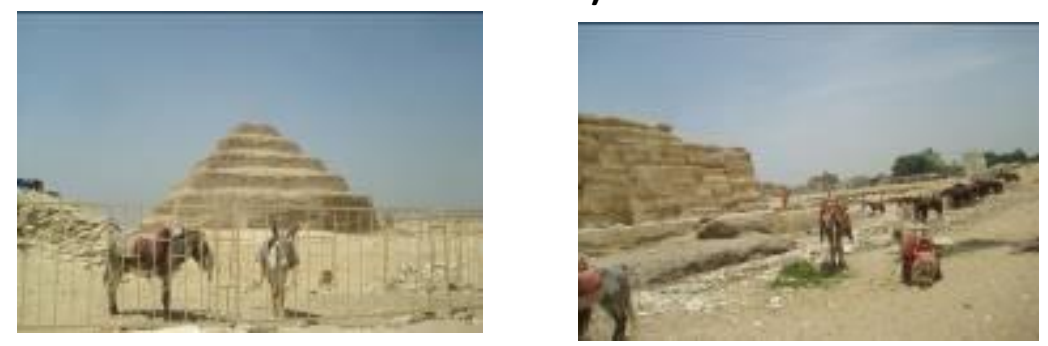


\section{Source: Researcher}

Many of the new buildings such as The Pyramids administrative buildings, Khufu Solar Boat Museum, the police station and the storage buildings make negative impact on the area, since these buildings are not suitable for the historic context of the area from form and infra-structure points of view. The roads which penetrate the heritage districts create developmental pressure too; such as the case with The Pyramid Street and Sahara City Road, even The Sphinx Road which extends to the Menkaure Pyramid. [ Figures 8, 9] ${ }^{6}$
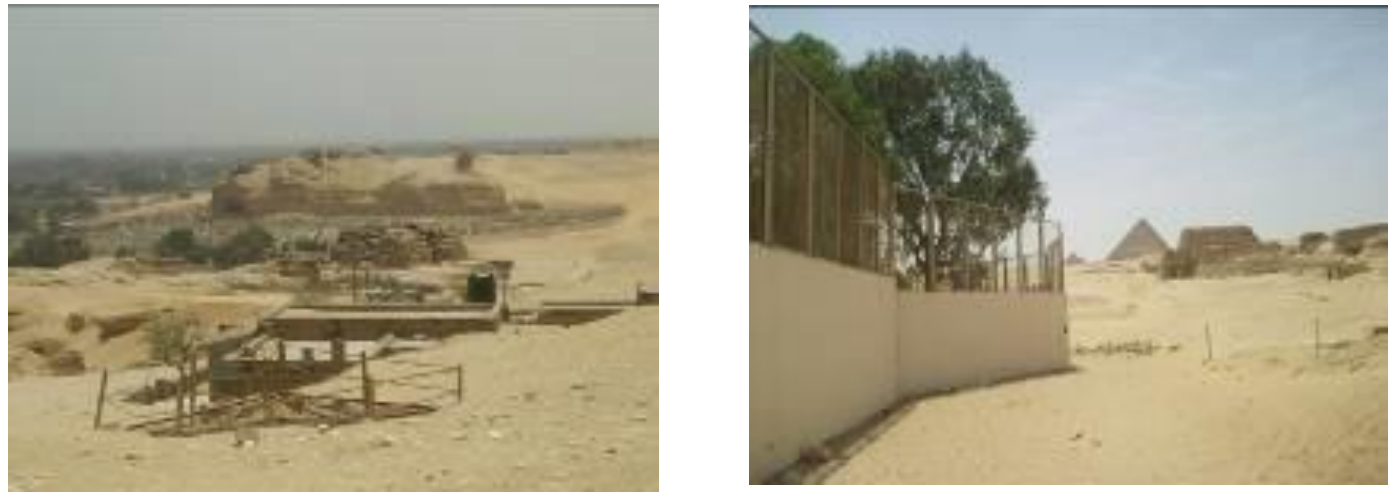

Figure 8, 9: Unsafe fences for The Pyramids area from Nazlet El Seman

Source: Researcher

5. Urban growth on the zones attached to The Pyramids 
From the sixties, the urban growth of the Giza governorate has massivelyincreased due to the establishment of The Cairo University bridge in 1960 where many new areas evolved after Cairo and Giza governorates were connected through the bridge. Then the $6^{\text {th }}$ of October bridge was constructed, which made traffic easier between many urban areas. However, The Pyramids area started to expand randomly, even the agricultural lands in the area have faced a lot of infringement. This was due to the unplanned districts which appeared to offer touristic activities at the historic area of The Pyramids. Most of the misplanning was caused by the owners being residents in Haram and Faysal streets; which are the two main streetsin the area. Secondary roads that weren't originally planned have also evolved, which resulted into a lot of slums
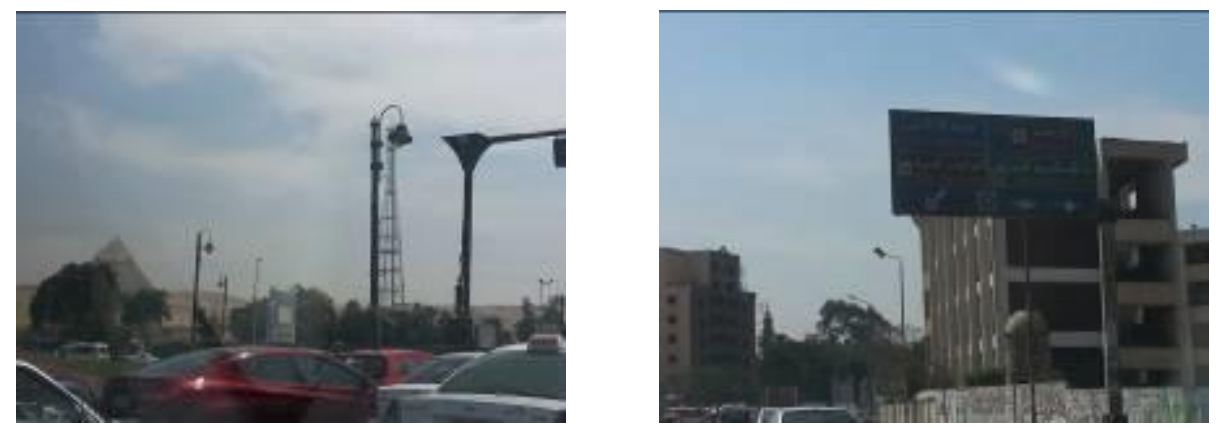

around the heritage zones. These slums have actually reached $70 \%$ of the 
built area in Giza. ${ }^{7}$ [ Figures 10, 11]

Figures 10, 11: Unplanned roads at the heritage districtSource: Researcher

\section{Informal urban crawl on the heritage district}

After the area transformed from a state of hard accessibility into an easy one, thanks to the constructed bridges and roads, it became an attractive residential area. Even the surrounding agricultural areas contain now residences near to these roads. Inthe year 1983, The General Organization for Urban Planning in Egypt created a masterplan for Greater Cairo, including Cairo and Giza governorates. The plan showed new roads such as The $26^{\text {th }}$ of July Corridor in addition to phase 2 of the subway, and The Ring Road. These roads enabled people to take the new districts as their residence zones; as in the case of The $6^{\text {th }}$ of October and Sheikh Zayed cities andPyramids Gardens neighborhood. [ Figures 12, 13, 14] 

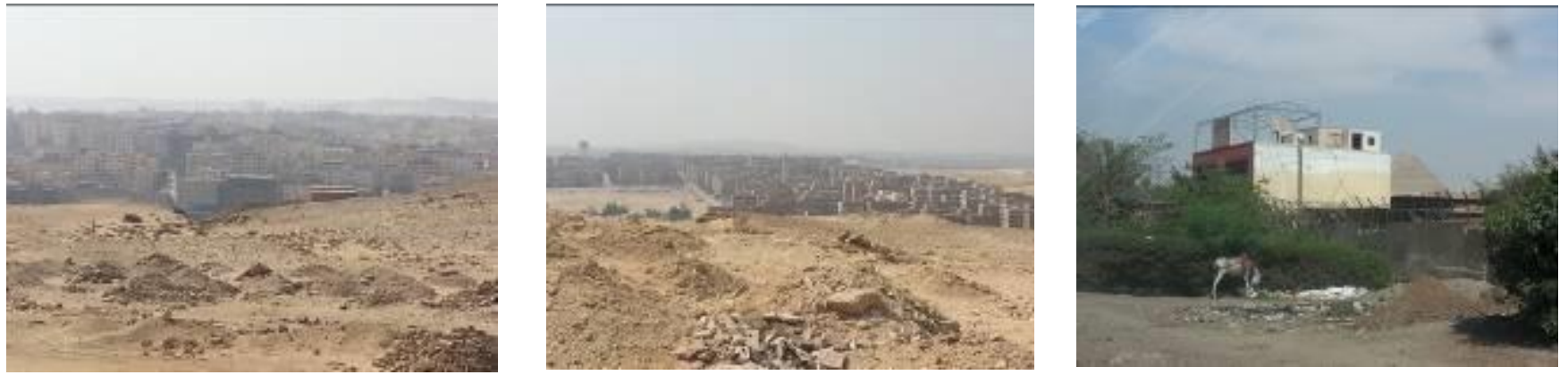

Figure 12, 13, 14: New urban areas attached to the heritage districts

Source: Researcher

Among other aspects making that urban pressure, is the proximity between Cairo and Giza governorates, leading to internal migration, especially that Cairo has alot of job opportunities from one side, and from the other side; Giza has a wide industrial zone perceived by many labor. From that point, the urban expansion increased to receive all those migrators, the districts have even expanded upon the agricultural lands. Many slums also spread without infra-structure causing another problem of increasing the ground water. In order to save the heritage district from theground water, a formal drainage network was constructed at Nazlet El Seman and Nazlet El-Batran 
areas. Governments one after another started to determine urban growth directions, to prevent the urban crawl on the heritage district, so they added borders to the historic zone and made a re-planning for the urban districts which are attached to this heritage district. The goal was to organize dealing with both the historic and new urban districts, but those borders resulted into a high density of residence, creating thus another form of pressure on the infra-structure and traffic in the area. ${ }^{8}$

\section{Threats caused by urban crawl on the heritage districts}

UNESCO classified many threats that have showed up at The Pyramids historic district. If those threats are studied and resolved, the required master plan can be created and the urban crawl problem can be controlled. The points of threat discussedcan be summarized as follows:

- Urban crawl of Nazlet El Seman, Nazlet El Batran, Kafr El Gabal, Kafr Ghataty and Mansheyet El Bakri, towards the eastern plateau at The Noblestombs and the Great Pyramid of Giza, in addition to The Sphinx

- Land use pressure (tourism and hospitality) 
- Official residences of military officers in El-Remaya square, in addition to Pyramids Gardens neighborhood at the north of the Giza Plateau and SaharaCity compound at the south

- Roads that penetrate The Plateau, such as The Pyramid Street and The SphinxRoad

- New buildings which were constructed upon The Plateau such as the inspectorsadministration office, the police station and The Presidential Palace ${ }^{9}$

\section{Previous efforts in the conservation of the heritage district}

The Archeology Center at The Faculty of Engineering of Cairo University was asked to prepare an integrated project to conserve The Pyramids Plateau in 1993. TheSupreme Council of Antiquities was the supervisor and owner of this project. This project is considered the most integrated one done to a world heritage site in Egypt, with a full site-management plan $^{10}$, and a set of documents that were prepared to finalize the project. These documents are:

- The Plateau masterplan - primary planning and coordination 
with the generallayout of the area

- Detailed program of masterplan implementation

- Study of the roads around The Plateau

- New proposed buildings and visitor centers down to The Plateau and around it

- Basic design of buildings at The Plateau

- Fences designs in addition to proposed circulation

- Lighting design

- Plateau survey

- Soil mechanics and geological study of The Plateau

- Feasibility study - cost analysis

- Time of implementation

- Site commission

- Administration and security points at The Plateau 
- Economical benefits of the project ${ }^{11}$

The project depended on taking a record of the existing condition, and was designed while considering this condition among many other aspects. The aspectsconsidered in this project can be listed into ${ }^{12}$ :

a- Existing condition record:

- Existing monuments at The Plateau which formulate the historic district and arethe product of humanity

- The Pyramids Plateau

- A visual study from and to The Plateau

- Surrounding urban area which intersects with The Plateau

The previous aspects were classified to multi levels of protection for the heritagedistrict and its buffer zone. A conservation plan was prepared to include all of thoselevels, then a complete replacement plan was carefully designed, including the removal of unsuitable structures from The Plateau. ${ }^{13}$ 
b- The Supreme Council of Antiquities Guidelines, which set the design criteria for themaster plan from roads, to circulation, lighting requirements, and new buildings.

c- The UNESCO plan for The Plateau which advised on making three new cultural centers joined together with The Ring Road. Those centers also needed to be related tocity entrances, while preventing traffic of cars and buses, and removing all the new structures from The Plateau. The full master plan was produced and then a detailed plan for every part followed. The masterplan was formulated over two stages. The first was shaping the outline and conditions in addition to identifying the master plan components. The second phase was proposing a matrix of solutions and alternatives that focused on the means of reaching The Plateau, added to the locations for buildings and fences, the lighting systems, and the environmental protection approach. The project consultants named the project 'unfinished conservation', since the first stage of the project was applied in 26 months instead of 6 . The contract which contained many stages was never fulfilled; as only the first stage was implemented. Until now, this project has notbeen completed, despite several restoration and security procedures applied to The 
Plateau as separate projects. ${ }^{14}$

\section{An approach to manage urban crawl}

To manage urban crawl, a guideline must lead the solution; in order to treat allthe connected aspects which are related to the heritage district. This guideline shouldconsist of the following procedures:

- Protecting the heritage district

- Restoring the relation between the district and its natural context

- Controlling the traffic from and to the district

- Emphasizing the environmental approach in the heritage district and itssurroundings

- Solving garbage problems

- Solving urban deterioration

- Introducing suitable cultural and touristic activities

- Preparing the administration requirements (centers and human resources) 
- Urban planning of The Plateau

- Controlling animal circulation at The Plateau

- Protecting The Plateau from urban crawl and residential districts expansions

- Enabling suitable accessibility and roads from the different directions of ThePlateau ${ }^{15}$

\section{Proposal for managing urban crawl on heritage districts and attached areas}

To manage urban crawl, many aspects should be introduced. The proposed management plan consists of three parts starting with the identification of the heritagedistrict and its required formal and informal borders. The plan can be explained as follows:

\section{Part one}

- Site description with information, photos, and maps

- Cultural information concerning the architecture and archeology of the site

- Environmental information on the site of The Plateau and 
studies of the seismicarea

- Land use history in addition to existing social and cultural activities

\section{Part two}

- State of conservation

- Problem identification at the heritage district

- Risk analysis of the district to prioritize solutions

- Identifying site significance

- Evaluating district features from original values in reference to natural materialsand craftsmanships

- Identifying the cultural value of the district and its universal value

- Setting a plan for removing the new structures

- Monitoring urban and land use to reduce their negative impact

- Preparing economic values for the required budget for conservation anddevelopment

- Identifying objectives for site management 
- Preparing a preventive conservation plan

- Stopping the urban crawl by the power of legal regulations

\section{Part three}

- Designing a management plan with short, medium, and long terms

- Preventing the licensing of buildings in the attached zones to decrease pressurein the heritage districts

- Making urban renewal at the slums of suitable infrastructure at the heritagedistrict surroundings

- Removing the unsafe slums and residences which were constructed withoutinfra-structure studies and providing alternative residences outside the area

- Controlling traffic to decrease the movement through the surrounding roads

- Initiating new corridors that can connect with The Ring Road in order to prevent the heavy trucks traveling on Fayoum Road which is very close to theheritage district

- Considering the whole area in the governmental masterplans 
- Officially providing the required services for tourism and administrationthrough suitable building structures

- Keeping the existing fence to stop the urban crawl until the complete planning for the area is produced, as these fences despite being unsuitable - do play animportant role in protecting the area from urban crawl

- Joining the time schedule with its short, medium, and long terms; with themanagement plan

- Determining the required Budget

- Using modern technology in monitoring the heritage district through satellites;including:

$\circ$ Users' monitoring

- Land use monitoring

○ Spotting urban crawl on the heritage district

- Identifying parking and shopping areas, and roads

- Monitoring the progress of urban crawl after implementing the solutionstep by step with the 
different management terms

- Measuring the dynamic operations of the development pressure byremote sensing ${ }^{16}$

- Creating reports through monitoring indicators to identify changepatterns ${ }^{17}$

- Identifying certain references that are used to create the plan so that it can be used and developed through scientific research for the purpose of conserving The Pyramids heritage district. ${ }^{18}$

\section{Results}

- The main cause of deterioration for The Pyramids heritage district came from thinking in every district in separation from its surrounding and original context

- Development cannot be implemented if assumed that it can act through a single stage; because that urban crawl has exceeded the level of physical effect 
- Mismanagement and miss-monitoring comes in result of thinking of every monument separately

- Without a border, the heritage district can't be integrated with the surrounding urban areas, especially that what is attached to it are poor neighborhoods resided by culturally unaware communities

- Unmonitored licenses can cause big damage more than informal light structures

\section{Recommendations}

- Using information technology in management and monitoring of heritage districts

- Making strict laws for land use at the heritage districts and attached areas

- Having at least a minimum level of management being applied to heritage districtswhile considering them as world heritage

- Inscribing urban and monument conservation in the governmental budget 
- Integrating public and private sectors in managing heritage districts

- Using heritage districts in sustainable ways

\section{References}

${ }^{1}$ Jukka Jokilehto, What is OUV? Defining the outstanding universal value of cultural world heritageproperties, Hendrik Bäßbler verlag, Berlin, ICOMOS, 2008

${ }^{2}$ Whc.unesco.org/list

${ }^{3}$ Strategic approach to Egypt's cultural Heritage, Ministry of Communication and InformationTechnology, Cultnat, 2001

4 Monitoring World Heritage, World Heritage Center (WHC), UNESCO, 2004

${ }^{5}$ El-Sherbiny, E. Feakry, M., Human Factor effect on conservation projects, a comparative analysis between pyramids districts and Serabit Al Khadem, Sinai, Dubai Scientific Conference, 2007, page480 
${ }^{6}$ Masoud, O., Conservation process activation at valuable districts, special mention to historic Cairo,2003, page 42

${ }^{7}$ The General Organization for Urban Planning, Cairo masterplan

${ }^{8}$ El-Sherbiny, E. Feakry, M., Human factor effect on conservation projects, a comparative analysisbetween pyramids districts and Serabit Al Khadem, Sinai, Dubai Scientific Conference, 2007

9 UNESCO, Partnerships for World Heritage Cities Culture as a Vector for Sustainable UrbanDevelopment, World Heritage Center (WHC), UNESCO, 2003

${ }^{10}$ Pyramids Plateau Master plan, final report, Center of Archeology, Faculty of Engineering, CairoUniversity, 1995

${ }^{11}$ Previous reference, page 3

12 Pyramids Plateau. Detailed project to implement the Master plan, final report, Center ofArcheology, Faculty of Engineering, Cairo University, 1994, page 7

${ }^{13}$ Abdel Qader, N. Al-Tuny, S., Three Egyptian experiments, Ninth Conference of Architects, 1999 
${ }^{14}$ Abdel Qader, N. Al-Tuny, S., Previous reference, 1999

15 Pyramids plateau. Master plan, final report, Center of Archeology, Faculty of Engineering, CairoUniversity, 1995

${ }^{16}$ Monitoring World Heritage, World Heritage Center (WHC), UNESCO, 2004, page104

${ }^{17}$ Previous reference, page 105

18 Bernard M. Feilden, Jukka Jokilehto, Guidelines for World Heritage Cultural Sites, 1993, page 38 